\title{
Ni bandas ni pandillas: la miopía de las teorías de las subculturas para explicar la violencia juvenil
}

\author{
Silvia Guemureman*
}

\begin{abstract}
Resumen
En este artículo propongo, a partir del estudio de dos casos actuales y recientes de violencia juvenil protagonizados por jóvenes de Argentina, demostrar que las teorías de las subculturas, desde el modo en que nominan al problema, son insuficientes para dar cuenta del fenómeno de la violencia expresada por adolescentes y jóvenes. Esto estaría denotando otros móviles de carácter más estructural, queatraviesan transversalmente a todos los sectores sociales. De allí que sea necesario buscar otras explicaciones para dar cuenta de un fenómeno tan preocupante, que no sólo interpela al sistema penal sino a la sociedad entera en búsqueda de respuestas activas. La "siempre lista" alternativa de endurecer el sistema penal no soluciona el problema sino que lo profundiza, ya que recae sobre los segmentos socialmente más débiles y no aborda el tema central de la violencia estructural y el malestar en la cultura.
\end{abstract}

Palabras clave: Violencia juvenil, sistema penal, subculturas, adolescentes y jóvenes, violencia estructural, malestar.

\begin{abstract}
From the study of two current and recent cases of youth violence in Argentina, in this article I intend to demonstrate that subculture theories, as they nominate the problem, are insufficient to report on the violence phenomenon expressed by adolescents and young adults. This may be denoting other more structural mobiles that crosses in a transversal way all the other social sectors. Taking this into consideration, it is necessary to search other explanations to report on such a worrying phenomenon, that not only appeals to the Penal System but to the hole society in search for active answers. The "always ready" alternative of harding the Penal System does not solve the problem but makes it deeper, since it affects the weakest social segments and does not deal with the structural violence as the central subjetc and Civilization and Its Discontents.
\end{abstract}

Key words: Youth violence, Penal System, Subcultures, Adolescents and young adults, Structural violence, discontent.

* Lic. en sociología. Especialista en problemáticas sociales infanto-juveniles. Investigadora de CONICET en el Instituto de Investigaciones Gino Germani-Facultad de Ciencias Sociales/ Universidad de Buenos Aires. sguemure@mail.retina.ar 
Ni bandas ni pandillas: la miopía de las teorías de las subculturas para explicar la violencia juvenil - S. Guemureman

“La palabra «libertinaje» es un modelo perfecto del lenguaje teledirigido a minar la confianza en la responsabilidad, la educación y el modelo que les hemos dado a nuestros hijos adolescentes. Porque, encarnada en menores de edad, la libertad se convierte demasiado fácil y peligrosamente en libertinaje. Y el libertinaje es el hijo bobo de la libertad. Y la libertad nunca es cómoda, nunca es fácil, nunca es lisa: tiene arrugas y pliegues de los que a veces salen brujas. Los cazadores de brujas lo saben". (Sandra Russo, "Adolescentes" Nota publicada en el Diario Pagina 12, 29/04/2006)

La sociología ha desarrollado teorías para explicar el fenómeno de la delincuencia juvenil. Gran parte de las explicaciones propuestas han "comprado" la teoría de las subculturas criminales para dar cuenta del fenómeno de los adolescentes y jóvenes que incurren en acciones contrarias a las normas en forma grupal y buscando algo más, o algo distinto de la mera consecución de un botín material valioso. La investidura de valor, según coinciden las corrientes de pensamiento inspiradas en lecturas de tipo psicosocial estaría dada por otras atribuciones distintas del valor económico y/o valor de mercado. Esto ha llevado a uno de sus teóricos pioneros y fundamentales a expresar que esta delincuencia es "antiutilitaria", "negativa" y "maliciosa" (Cohen, A. 1955).

Estas tres características de los actos de vandalismos cometidos por subculturas delincuentes han sido sistemáticamente asimiladas a las clases bajas y, en esto, toda la lectura es coincidente (Cohen, 1955; Sykes y Matza, $1957<2004>$, Cloward y Ohlin, 1960; David, 1969). Incluso, estudios más recientes (Spergel, 1990 $<2002>$ ), que coinciden en sus limitaciones, no dejan de focalizar el mismo aspecto y, por ende, más que salir del círculo, lo realimentan.

Sin pretender convertir a este en un artículo de revisión crítica acerca de las teorías de las subculturas criminales, especialmente aquellas que buscan establecer vinculaciones entre la delincuencia juvenil y la formación de bandas y pandillas, sí se busca localizar y propender a otras explicaciones sobre un fenómeno que es 
mucho mas amplio que el de la delincuencia juvenil, pero que lo abarca y subsume, y es de la violencia juvenil, patrimonio no solo de las clases pobres, sino también de las clases ricas o, como una vez dijera un presidente de la Argentina, "no solo de los niños pobres que tienen hambre, sino de los niños ricos que tienen tristeza". Ubicar la violencia en vez de la delincuencia parece una invitación a interpelar a otros actores como protagonistas estelares.

\section{Los hechos}

"No puede Ud. imaginarse lo estúpido que me siento cuando les hablo a mis hijos de compromiso. Para ellos, es una virtud abstracta; no la ven en ninguna parte."

(Citado en Sennett, La Corrosión del Carácter)

En la Argentina, en el último tiempo, se han producido algunos episodios con gran repercusión pública que deben convocarnos a la reflexión. Aunque teorizar sobre el presente tenga sus limitaciones inherentes, dado el impacto que han provocado en la sociedad, cabe hablar de los casos de Ariel Malvino y de Matías Bragagnolo. En el primer caso, se trata de un joven de 21 años que, estando de vacaciones en Ferrugem (una playa brasileira) fue muerto en un episodio de "pelea generalizada" en enero del 2006. El otro, más reciente, de mediados de abril, se refiere a un adolescente de 16 años que murió como consecuencia de una pelea entre chicos, aunque aún las causas de su muerte permanezcan confusas ${ }^{1}$.

En ambos casos, si bien se trata de dos jóvenes muertos, víctimas de violencia de pares, las circunstancias los diferencian. En uno de los casos, el agravante de haberse producido el evento en otro país y habiéndose visto involucrados miembros procedentes de familias prominentes de la clase gobernante de una de las pro-

1 Los informes de los peritos médicos coinciden en señalar un edema pulmonar como el desencadente de la muerte de Matías. Más allá de la controversia que este dictamen ha generado, de la asociación que se ha pretendido establecer entre el consumo de alcohol, bebidas energizantes y la violencia producida, lo cierto es que, como recientemente han dicho los padres de la víctima, "Está claro que si Matías no falleció de muerte natural, se trata de un homicidio". 
Ni bandas ni pandillas: la miopía de las teorías de las subculturas para explicar la violencia juvenil - S. Guemureman

vincias de nuestro país ${ }^{2}$ le ha conferido características peculiares que reeditan otros casos criminales famosos y que convocan a desplazar el eje del análisis de la vinculación siempre compleja entre el delito y el poder político y económico ${ }^{3}$, en vez de situarse en la cuestión que interesa aquí, y es el de la violencia juvenil.

No se desconoce la dificultad que presentan situaciones como la descrita para llegar a un estado judiciable, y, más aún, lo difícil que resulte que los responsables en términos jurídicos sean efectivamente sancionados de acuerdo al reproche que los estatutos penales prevén en casos semejantes ${ }^{4}$. No obstante, independiente de los resultados judiciales -que por otro lado están hablando de otro fenómeno- lo que importa aquí es desentrañar el porqué de la violencia juvenil como violencia gratuita, desproporcionada, antiutilitaria, negativa y hasta letal, inexplicable desde las teorías que han hecho de la deficiencia de la socialización y la deprivación sus principales argumentos explicativos.

El caso de Matías B. es si se quiere, más escalofriante aun por la oportunidad de identificación que ofrece. El hecho de que Matías pertenezca a la clase media y que su muerte se haya producido en circunstancias comunes para cualquier adolescente de

2 Baste decir que uno los testigos citados, perteneciente al grupo de correntinos involucrados en la pelea grupal cuya consecuencia fue la muerte de Ariel, es hijo del entonces subsecretario de turismo provincial quien, al ser citado su hijo, renunció al cargo y otro sobrino de un ex gobernador de la provincia de Corrientes. Asimismo, los padres de los principales sospechosos son conocidos empresarios locales que han incursionado en la política local.

3 Una vez más, como en el asesinato de María Soledad Morales en la provincia de Catamarca, se habló de "los hijos del poder". Recientemente un artículo daba cuenta de "Las tropelías de los jóvenes del poder" recogiendo testimonios de vecinos quienes, por temor a represalias, no quisieron ser identificados y que coincidieron en afirmar que era frecuente que algunos de los sospechosos del crimen fueran protagonistas de episodios violentos "pero esas cosas se tapan porque son nenes bien, pibes con guita que creen los dueños del mundo y hacen lo que quieren porque llevan un apellido famoso" (La Nación/Información General, Pág 12, 1/02/2006).

4 La justicia brasileira, a partir de las pruebas recolectadas en la etapa de instrucción, pediría la detención, la captura internacional y la extradición de tres de los cuatro muchachos correntinos imputados de haber participado en la muerte de Ariel Malvino. Hasta ahora, los imputados habían sido indagados por la con-juez que lleva la causa en la provincia de Corrientes, y habían respondido un cuestionario que llegó por vía diplomática desde Brasil. 
su clase, en el devenir del usufructo del tiempo libre, lo hace terriblemente cercano y aterrador.

Los ecos de la muerte de Matías han despertado al aletargado coro de aquellos que braman por el endurecimiento punitivo hacia los jóvenes y por la baja de imputabilidad penal, aun cuando, en este caso, no sea el disparador un episodio que involucre a esos "feos, sucios y malos" de siempre, sino a otros sujetos jóvenes, que, aun con leyes más duras, siempre estarán preservados de la selectividad del sistema penal y aun en el peor de los casos podrán, como refiere lúcidamente Melossi, "comprar todo el stock de garantías disponibles en el mercado" (Melossi, 1997: 75). En el caso de Ariel, el proceso judicial tuvo otro cariz, vinculado a interpelar al poder de turno y sus prolongaciones que hizo que, antes de asumir la causa judicial, varios jueces rehusaran asumir en carácter con-jueces ${ }^{5}$. Es interesante, en este caso, pasar revista a las excusas presentadas que no hablan de otra cosa sino de la distribución artificial de inmunidades y responsabilidades penales que "es un aspecto de la 'distribución política' de la riqueza social ampliamente entendida" (Pavarini, 1994: 19).

Los dos casos tienen como común denominador la violencia entre pares por motivos absolutamente triviales y circunstanciales. En ninguno de los casos se trata de enfrentamientos entre bandas y/o pandillas rivales que "se la tienen jurada". No hay en estas peleas una delimitación de territorio. Más bien, de lo que surge de la información periodística, se trata de episodios en que el motivo de la pelea es insignificante e irrelevante ${ }^{6}$, pero en don-

5 El primero en desistir fue el juez natural de la causa, el Dr. Carlos Soto Dávila, titular del juzgado federal de Corrientes. Luego, se excusó la primera de la lista, María Itatí Silveyra de Moulín. Lo mismo hizo el segundo de la nómina, Ángel Machado. Todos adujeron vinculaciones e intereses con las familias de los imputados. Finalmente, la abogada María Esther Campanher, aceptó convertirse en la jueza ad-hoc.

6 En el caso de Ariel, todos los testimonios son coincidentes en que él no participó de ninguna pelea, sino que fue agredido. En el caso de Matías, "todo habría comenzado con el intento por apropiarse del celular de la víctima. La pelea que terminó con la muerte de Matías, de 16 años, se originó cuando uno de los jóvenes que ahora está alojado en un instituto de menores, atacó a Matías para robarle su teléfono móvil" ( $L a$ Nación, Información General, Pág. 15, 26/4/2006). 
Ni bandas ni pandillas: la miopía de las teorías de las subculturas para explicar la violencia juvenil - S. Guemureman

de los participantes ponen en juego una demostración de fuerza sin medición de consecuencias, vil sustituto de una virilidad ya no demostrable a través de las conquistas sexuales. El "ethos" hedonístico propio de la cultura adolescente se caracteriza por un modo particular de resolver por parte de los jóvenes sus tensiones con el mundo adulto y en tal carácter desafiar el orden heredado con actos transgresores. Según David (1974: 65), las acciones más frecuentes de transgresión de esa cultura adolescente -no en vano, nominada como "cultura" y no como "subcultura"- se vinculan a hechos tales como abuso de reglamentaciones de tránsito, entre las que se encuentran las corridas de 'picadas', sustracción de automotores con la finalidad de paseo -en muchos casos, a los propios padres sin licencia habilitante-, el espíritu competitivo, el conflicto sobre valoración del sexo y expectativas relativas al mismo y el abuso de bebidas alcohólicas. Treinta años después, aún podríamos suscribir esta enumeración y añadir, a este listado, los matices que ha impreso el neoliberalismo en las subjetividades de los jóvenes, en el sentido de una cultura descartable, flexible $^{7}$, provisoria, ocasionando lo que con lucidez Sennett ha denominado "la corrosión del carácter", entendido este como la conexión con el mundo, como el ser necesario para los demás, producto de una sociedad impaciente y centrada en lo inmediato: " ¿Como decidimos lo que es de valor duradero en nosotros? (...) Cómo perseguir metas a largo plazo en una economía entregada al corto plazo? ¿Cómo sostener la lealtad y el compromiso recíproco en instituciones que están en continua desintegración o reorganización?" (Senett, 2000: 10).

Sin embargo, lo que estos dos casos han hecho visible es la existencia de otros casos que quizás por no haber tenido consecuencias fatales -estrategia de marketing periodístico- no habían

7 Dice Senett: "[...] En la actualidad, el término flexibilidad se usa para suavizar la opresión que ejerce el capitalismo. Al atacar la burocracia rígida y hacer hincapié en el riesgo, se afirma que la flexibilidad da a la gente más libertad para moldear su vida. De hecho, más que abolir las reglas del pasado, el nuevo orden implanta nuevos controles [...]" (Senett, R. La corrosión del carácter. Las consecuencias personales del trabajo en el nuevo capitalismo. Editorial Anagrama, Barcelona, 2000 Pág. 10). 
trascendido a la opinión pública ${ }^{8}$. Y estos casos, que no son pocos, dan cuenta de otros episodios en donde la violencia entre pares, gratuita y antiutilitaria, fue la animadora principal, desplazando el eje de la interrogación sobre las "causas" de estos fenómenos a explicaciones que reenvían a revisar el malestar en la cultura, el contexto y procesos complejos de construcción de individuos y desubjetivacion de identidades juveniles ya no investidas de valores "universales".

O sea que los episodios que han salido a la luz operan como emergentes de una violencia estructural cuyo origen está en otro lado. Que hayan sido noticias y, por ende, que hubieran trascendido a la opinión pública se debe a que se han convertido en tema de la comunicación. Al respecto, dice de Giorgi que "la opinión pública se interesa solo en los temas que interesan a la opinión pública. Lo demás es invisible puesto que de eso no se habla -sea violencia o malestar-, se torna en un problema psicológico" (de Giorgi, 1997: 87-88), aunque también advierte que las modalidades del tratamiento comunicativo de eventos que son presentados como violencia "producen a su vez amplificaciones y reducciones que se interponen como obstáculos respecto de los fenómenos. La sociedad aparece invadida por la violencia hacia los menores -o de los menores- o como invadida por violencia que se ejerce sobre cosas y personas y que es identificada con la violación de normas jurídicas específicas. Se desmembra el pro-

$8 \quad \mathrm{Al}$ respecto, el diario Clarín, en la nota del 16/04/2004, "Violencia por nada: ¿qué hay detrás de las nuevas peleas juveniles?", da cuenta de tres casos con desenlace diferente: el caso Ronzoni, en el que por un adoquín el adolescente estuvo a punto de perder un ojo a manos de otro joven de excelente posición económica y rugbier de la selección nacional juvenil; el caso de otro chico al que "le bajaron los dientes de una trompada en la cara", y los autores fueron chicos procedentes de un barrio privado y de un buen nivel económico. El tercer caso tuvo desenlace fatal y fue el de Marcos Spedale, de 16 años en Córdoba, quien fue atacado a golpes por un grupo de jóvenes en un metegol de un barrio paquete cordobés. En este caso, estaba implicado el hijo de un ex legislador y el hijo de una funcionaria judicial. El diario La Nación, en la nota "Hechos que precedieron a la muerte de Ariel" agrega a la lista el caso de Ariel Sciulli, quien, a raíz de los golpes recibidos en la puerta de un boliche bailable en el barrio porteño de Palermo, estuvo a punto de perder la retina de un ojo y le fue roto el tabique nasal (La Nación / Información general 25/03/2006). 
Ni bandas ni pandillas: la miopía de las teorías de las subculturas para explicar la violencia juvenil - S. Guemureman

blema de la violencia y la comunicación se ocupa solo de determinadas formas de violencia, y (....) en este sentido, no se logra observar la violencia a base de una observación de la estructura de esta sociedad (....): se construyen conexiones reductivas entre eventos que llevan a determinación de causalidades simplificantes" (Pág.: 87).

Probablemente, este sea el saldo que nos dejan estos episodios y que nos permiten centrar la discusión donde se debe, y no caer en los falsos ejes que se nos proponen y reproponen cada vez, cuando las elites de poder, que no desarrollan un consenso en torno a la definición del problema, sí "lo utilizan para mantener o expandir intereses particulares y programas que sirven para acentuar el aislamiento o el castigo de jóvenes pandilleros" (Spergel, 2002:63). Máxime cuando, independientemente del episodio que haya sido detonante, la respuesta estatal termina siendo coactiva haciéndose eco de las posiciones más duras respecto a cómo "combatir el problema de la inseguridad", que soslayan los verdaderos orígenes del problema de la inseguridad principalmente social y agotan su imaginación y su artillería en las propuestas de modificar el sistema penal, endurecer las penas y bajar la edad de imputabilidad para los adolescentes.

\section{Teoría de las subculturas delincuentes ¿qué dicen? Un recorrido}

"La deriva está de camino entre la libertad y el control. Se base en una zona de la estructura social en la que el control se ha relajado, lo que está unido a los infructuosos intentos de los adolescentes para organizar una subcultura autónoma que representaría una importante fuente de control en torno a la acción ilegal. El delincuente está momentáneamente en un limbo entre el ámbito de lo tradicional y el de lo delictivo y responde alternativamente a las exigencias de ambos, coqueteando ahora con uno, luego con el otro, pero postergando todo compromiso, eludiendo las decisiones. Así oscila a la deriva entre el comportamiento delictivo y el tradicional." (Matza, 1964) 
Antes que pasar revista a las teorías que se ocuparon de las pandillas juveniles, conviene hacer un recorrido a las teorías de las subculturas delictivas. El punto de partida, es que se trata de modalidades de conducta orientadas a solucionar problemas de "adaptación". Es Albert Cohen quien, en su famoso libro sobre los delincuentes juveniles y la cultura de bandas", da una definición fundacional: "Empleamos el término "subcultura» cuando estamos interesados en una cultura en relación con otra matriz y con un sistema social más grande en cual se enclava". Luego expresa la hipótesis de que las subculturas delictivas son producto del conflicto entre una cultura de clase obrera y otra de clase media. Según sostiene, en lo que sería una aplicación de la teoría mertoniana de la anomia, los sujetos procedentes de la clase obrera son socializados en las instituciones con los valores de la clase media que, inexorablemente, los frustran porque estructuralmente no están en condiciones de competir con la misma perfomance. Esta "frustración de status" sería el móvil para que los adolescentes reaccionen colectivamente ${ }^{10}$ contra las normas, invirtiendo los valores de clase media y, consecuentemente, afirmando una cultura maliciosa (se busca el reto por el reto), hedonista (busca el placer y la satisfacción inmediata), no utilitaria (la ecuación de costo-beneficio no se hace con arreglo al lucro o utilidad en términos de mercado), negativista (es contraria a las normas) versátil (es un comportamiento diverso, no especializado) y a corto plazo (no hay planificación, «lo quiero todo, lo quiero ya»).

La teoría de Cohen ha sido muy cuestionada y rebatida por distintos aspectos, limitaciones y debilidades. Lo que interesa aquí es un aspecto en particular, y es la crítica que ha recibido por constituirse como formación reactiva y en "contra de" los valores de

9 Cf. Cohen, A. : Delinquent boys: the culture of the gang, Chicago, Free Press, 1955.

10 Constituyen "grupos de referencia", "[...] en los que el individuo en interacción con otros con similares problemas de ajustamiento, mediante un proceso de exploración mutua y de elaboración conjunta de una nueva solución, participará en el nacimiento de un nuevo grupo de referencia, de una nueva subcultura que sancionará sus actos y, en la cual, encontrará solución a su problema de ajustamiento" (Madrenas i Boadas, 1990). 
Ni bandas ni pandillas: la miopía de las teorías de las subculturas para explicar la violencia juvenil - S. Guemureman

las clases medias, en vez de localizar la subcultura como un modo de adaptación que visualiza en forma realista las posibilidades y oportunidades tangibles y al alcance de los jóvenes de clases bajas. Críticos mordaces, en ese sentido, han sido Sykes y Matza (1957) quienes rechazaron la hipótesis de que las subculturas delictivas invertían los valores socialmente aceptados. Ellos señalan que si los delincuentes realmente tuvieran valores opuestos tenderían a considerar moralmente correcto su comportamiento ilegal y no tendrían sentimiento de culpa o vergüenza alguna, pero la realidad demuestra que no es así, y que eso demostraría que los delincuentes seguirían detentando los valores socialmente dominantes aunque neutralicen sus efectos normativos a través de justificaciones morales. Sykes y Matza designaron como "técnicas de neutralización" estas estrategias justificativas $(2004<1957>)^{11}$. La similitud que encuentran entre valores delictivos y valores de la sociedad en general los ha llevado a reemplazar el concepto de subcultura delictiva por la idea de la subcultura delincuente, que subyace en la sociedad y opera subterráneamente. "Si el sistema valorativo se examina de cerca, se descubrirá que varios valores supuestamente delictivos son muy parecidos a los encarnados en las actividades de esparcimiento de la sociedad dominante". Y, bajo esta premisa, revisan la teoría de Thorstein Veblen sobre la clase ociosa dominante, en su "machismo, su ansia de temeridad y aventura, y su afición por el consumo ostentoso". Es interesante la observación que hacen sobre la sociedad, en el sentido, de que ésta no es homogénea, y sus valores tampoco lo son. Incluso al interior de los mismos estratos sociales hay contradicciones que se expresan en valores subterráneos ${ }^{12}$. Matza sostiene que se produce un juego dialéctico entre unos y otros valores y, en tal sentido, determinadas conductas tipificadas como desviadas no serían otra cosa que acciones que manifiestan la emergencia de

11 Sykes, G.-Matza, D.: "Técnicas de neutralización: una teoría de la delincuencia", en Revista Delito y Sociedad, Revista de Ciencias Sociales No 20, 2004 (artículo original, publicado en American Sociologycal Review Vol. 22 Agosto de 1975).

12 Matza, D.: "Juvenile delinquency and subterranean values", en American Sociologycal Review, vol. 26, 1961. 
los valores subterráneos fuera del momento y las circunstancias propicias. Agrega que la propia noción de subterráneo expresa una dialéctica permanente entre lo tradicional y lo desviado y, en el proceso de intercambio, ambos se modifican. Su observación de la cultura joven americana le permite afirmar que, no obstante las contradicciones, la mayoría de los jóvenes son tradicionalistas.

En reemplazo de explicaciones dicotómicas para dar cuenta de la desviación juvenil, Matza (1964) utiliza el concepto de deri$v a^{13}$-transcripto en el epígrafe que encabeza este apartado- concepto útil, ya que tiende un puente que acerca a los adolescentes orientados hacia un individualismo positivo y aquellos orientados hacia un individualismo negativo o coercitivo (Castel, 1995:469) ${ }^{14}$.

Matza deja en claro que "deriva no es compulsión, pero tampoco es libertad, ya que libertad es autocontrol (...). La deriva hacia la delincuencia se ve precipitada por «circunstancias accidentales e impredecibles»" (Matza, 1964).

La deriva, así entendida, puede dar cobijo a las acciones de los adolescentes de todos los estratos sociales y va en la línea de reafirmar que, entre los adolescentes de las clases bajas que son los criminalizados y los perseguidos por el sistema penal y los adolescentes de las clases medias, y de las clases altas, subyace esa cultura adolescente hedónica, con una temporalidad subsumida en la inmediatez, como señala Bleichmar (2005), quien añade al escenario un proceso de desidentificación agravado por el

13 No casualmente, "deriva" es el concepto que elige Senett para relatar la parábola del capitalismo flexible y a corto plazo en la vida de un trabajador, que no obstante ser exitoso conforme a las nuevas reglas, se siente a la deriva y, en tal sentido, asimila "cambio" a "deriva" y teme que sus hijos naveguen ética y emocionalmente, al no poder proporcionarle valores duraderos que los preserven de las ansiedades, confusiones y riesgos que implica la flexibilidad y el cortoplacismo.

14 Robert Castel, al distinguir ambos individualismos, expresa que el positivo está vinculado al creciente margen de autonomía y libertad que van ganando las personas. El individualismo negativo es coercitivo ya que se refiere a las personas que deben vérselas solas para arreglarse en todas las circunstancias de la vida, y surgen por ellos. "Individualismo negativo porque se definía en términos de falta: falta de consideración, falta de seguridad, falta de bienes seguros y vínculos estables" (Castel, R. 1995: 469). 
Ni bandas ni pandillas: la miopía de las teorías de las subculturas para explicar la violencia juvenil - S. Guemureman

hecho de que el país "se haya convertido en un lugar transitorio para los jóvenes que aun piensan en un futuro posible, y en un espacio sin sentido para quienes tienen vedada incluso esa perspectiva" (Bleichmar, 2005: 48). Si una característica distingue a los jóvenes procedentes de los sectores socialmente desfavorecidos ${ }^{15}$ es el fatalismo o, como Cohen mismo dice, "tienen una actitud realista acerca de sus posibilidades en la vida". Matza añade que el fatalismo crea un sentimiento de desesperación que hace que los jóvenes fatalistas y desesperados pasen al acto.

Cloward y Ohlin (1960) realizan un intento de articular las dos explicaciones que prevalecen en la academia para explicar el surgimiento de las subculturas, y concluyen afirmando que las subculturas delincuentes aparecen entre los delincuentes varones de baja clase social en los grandes centros urbanos. Dentro de las subculturas, distingue tres tipos: las criminales, las conflictivas y las replegadas, según la estructura de oportunidades diferencialmente distribuidas en la sociedad. Así, la subcultura criminal surgiría en un barrio integrado, en donde existan modelos criminales y facilidades para el aprendizaje; la subcultura conflictiva surgiría en los barrios bajos de las grandes ciudades caracterizados por la falta de unidad y cohesión. Estas comunidades no pueden proveer el acceso a los medios socialmente legítimos, pero tampoco garantizar oportunidades estables en las estrategias ilegítimas, de allí que "no haya un sistema criminal organizado" y las acciones criminales tienden a ser individuales, desorganizadas, mal recompensadas y desprotegidas. Esta es la subcultura que preocupa a la opinión pública justamente porque, al no tener referentes de

15 En este aspecto, me he tomado la atribución de reemplazar "muchachos de la clase obrera" por "jóvenes pertenecientes a sectores socialmente desfavorecidos", habida cuenta de que Matza escribió los ensayos a los que se ha hecho referencia entre las décadas del '50 y del ' 60 del siglo pasado, en que los soportes identitarios de la escuela y el trabajo eran fuertes, el estado de bienestar estaba en su apogeo, y aún podía hablarse de "clase obrera". Varias décadas después, el contexto ha cambiado, las reglas de juego son otras, la clase obrera -que iba al paraíso- ha desaparecido, y los modos de socialización de los jóvenes socialmente desfavorecidos se dan en otros ámbitos, entre los cuales imperan la informalidad, la precariedad, la inseguridad y la ausencia de proyectos y de futuro. 
integración, se manifiesta a través de acciones violentas y da lugar a la aparición de bandas callejeras. La subcultura replegada, en cambio, sería un tipo de adaptación en el cual confluyen la falta de acceso a medios legítimos de satisfacción de necesidades y la renuencia a utilizar medios ilegítimos por parte de los sujetos a causa de sus barreras culturales y las prohibiciones internalizadas en su proceso de socialización.

Se desprende, hasta aquí, que las explicaciones que se han dado sobre las subculturas adolescentes, aun las que aportan mayor cantidad de elementos para pensar el fenómeno de la violencia juvenil, no resultan suficientes para abordar inteligiblemente los hechos de violencia protagonizados por jóvenes que no ingresan en ninguna de las categorías de déficit, deprivación, carencia o frustración que subyacen en todas las explicaciones, sino que denuncian, y por eso son emergentes, otro tipo de problemáticas vinculadas al "malestar en la cultura", como pronosticó Freud, o como agudamente caracterizara un sociólogo contemporáneo, "malestar en la barbarie"16 y ¿por qué no? como el "malestar sobrante".

\section{Revisión crítica de la teoría de las pandillas: Un desafío inacabado}

"Cuando se habla de patotas, para mí es hacer una interpretación muy abusiva de algo que es prácticamente inevitable para cualquier adolescente: andar en grupo (...) Si interpretamos el grupo de pares y la calle, dos espacios de transgresión y horizontalidad como patota y violencia, estamos fritos". (Marcelo Urresti, Entrevista en Diario Página $12,23 / 04 / 2006)$

En un artículo escrito en 1990, el sociólogo Irving Spergel realiza una exhaustiva revisión bibliográfica sobre las pandillas juveniles y afirma que el fenómeno ha recibido poca atención en las últimas décadas, luego del apogeo sostenido a lo largo de las décadas de

16 Al respecto, Mires, Fernando El malestar en la barbarie. Erotismo y cultura en la formación de la sociedad política. Editorial Nueva Sociedad, Venezuela, 1998. 
Ni bandas ni pandillas: la miopía de las teorías de las subculturas para explicar la violencia juvenil - S. Guemureman

1950 a 1960. Esta falta de teorización se da a contramano de la preocupación que en torno al fenómeno existe siendo que hay consenso en que las pandillas juveniles de los ' 80 y '90 son más numerosas, más predominantes y más violentas que en los '50" (Spergel, $1990<2002>$ :56). Según Spergel, los estudios recientes realizados por cientistas sociales sobre estas cuestiones deberían ponerse al servicio de la formulación de políticas y programas que aborden y contrarresten el problema. A los efectos de realizar su propia contribución, Spergel revisa diez publicaciones sobre el tema ${ }^{17}$. En el recorrido planteado, Spergel posiciona su mirada en los métodos de investigación, la definición del problema, teorías, que sustentan los estudios, y luego en núcleos temáticos comunes; a saber: patrones de comportamiento, drogas, violencia, cuestiones de personalidad, racismo, y género.

De estas cuestiones es interesante rescatar las definiciones de pandillas. Algunas definiciones son más abstractas e inclusivas; algunas enfatizan determinados aspectos del comportamiento o de la formación de la pandilla. Así, James Short (incluido en la compilación de Huff) define el concepto "pandilla" en los términos más generales y neutrales, afirmando que una pandilla es "un grupo cuyos miembros se reúnen con alguna regularidad en el tiempo, sobre la base de criterios de membresía definidos por el grupo y estructura organizacional determinada por el grupo, generalmente con algún sentido de territorialidad. Esta definición incluye tanto conductas delictivas como convencionales, ya que ellas son las que generalmente deseamos explicar" (citado en Spergel: 58).

Prosigue Spergel comentando que la mayoría de los autores se resiste a definir las pandillas a partir de las acciones delictivas; más bien este podría ser un aspecto, pero no el principal aglu-

17 Nueve son estudios de caso: Elijah Anderson, Street Wise; Ko-Lin Chin, Chinese Subculture and Criminality; John Hagedorn, People and Folks; Mary Harris, Cholas; Martin Sanchez Jankowsky, Islands in the Street; Mercer Sullivan, Getting Paid; Carl Taylor, Dangerous Society; James Vigil, Barrio Gangs; y Terri Williams, The Cocoaine Kids. La décima, Gangs in America, por Ronald Huff, es un resumen de algunos de los mismos trabajos y estudios adicionales (Spergel, Op. Cit: 57). 
tinante. Así, una definición muy interesante es la de Harris que habla de la pandilla como "cualquier grupo cohesivo de adolescentes que tienen un grupo de normas de control y un sistema social específico de ese grupo. El grupo delincuente es distinguido de otros grupos juveniles sobre la base del producto delictivo de la interacción pandillera".

Jankowsky ha desarrollado una definición que enfatiza el carácter organizado de la estructura y actividad de la pandilla. "La pandilla es un «sistema social organizado» gobernado por una estructura de liderazgo con «roles definidos» que han sido legitimados. La pandilla organiza «individualistas desafiantes». Ella sirve a funciones comunitarias y, como organización, no está envuelta en una gran cantidad de violencia. La mayor parte de la violencia se debe a miembros actuando como individuos más que como agentes de la organización"18.

En el relato que hace Spergel, se pone de manifiesto que, aunque las definiciones de pandillas parecieran dar la impresión de una mayor amplitud, el fenómeno de las pandillas juveniles pretende ser reducido sistemáticamente a explicaciones causales y, entre éstas, dos ocupan un lugar destacado: la subclase y la desorganización social. "Los conceptos causales clave son: subclase, desorganización social, cultura, subcultura, organización y, en menor grado, factores de los pequeños grupos y de la personalidad" (Spergel: 60).

18 Recordemos la diferencia queCloward y Ohlin realizan entre la subcultura delincuente y la subcultura conflictiva, y parece replicarse el razonamiento: la estructura y la organización hace mermar la violencia, es la falta de red y de soportes lo que la hace aumentar. Entre estos factores, la desubjetivación ocupa un lugar preponderante. Duchasky -Corea, en Chicos en banda. Los caminos de la subjetividad en el camino de las instituciones (Editorial Paidós, Buenos Aires, 2002), dicen que "la desubjetivación nos habla de un modo de habitar la situación marcada por la imposibilidad, estar a merced de lo que acontezca habiendo minimizado al máximo la posibilidad de decir no, de hacer algo que desborde las circunstancias. Se trata de un modo que despoja al sujeto de la posibilidad de la decisión y la responsabilidad" (Op. Cit.: 72). Bleichmar (2005:80) alude a "cambios en la subjetividad", "procesos de des-subjetivación y resubjetivación", "subjetividad en riesgo", "deconstrucción de la subjetividad" para referirse a los efectos que en el psiquismo humano acarrean las transformaciones de fines del siglo XX y comienzos del siglo XXI. 
Ni bandas ni pandillas: la miopía de las teorías de las subculturas para explicar la violencia juvenil - S. Guemureman

Lo interesante, pese a lo insuficiente de estos estudios, es el hecho de que se "corren" de las teorías de las subculturas y sobre todo de las que hicieron de la delincuencia el principal factor explicativo y móvil. La tarea de pensar en dispositivos teóricos más adecuados al fenómeno de la violencia juvenil queda pendiente.

\section{Reflexiones finales: En la búsqueda de puentes para articular reflexiones y esquemas conceptuales de lectura y comprensión de fenómenos de violencia juvenil}

"El malestar es una fuerza que, siendo originariamente subjetiva, es -en determinados períodos- social y política. Puede hacer desear la barbarie cuando la cultura amenaza suprimir las pulsiones; puede hacer desear la cultura cuando la barbarie amenaza con desintegrar valores que se han probado necesarios para la convivencia." (Mires, 1998:10)

“El malestar sobrante está dado, básicamente, por el hecho de que la profunda mutación histórica sufrida en los últimos años deja a cada sujeto despojado de un proyecto trascendente que posibilite, de algún modo, avizorar modos de disminución del malestar reinante." (Bleichmar, 2005: 18)

Cada vez que un episodio protagonizado por adolescentes en forma grupal tiene consecuencias fatales, se habla de bandas juveniles, de pandillas criminales, sin detenerse demasiado a reflexionar sobre el carácter del episodio, sus implicancias y sus móviles. Se apela al común denominador de "banda" que, en la tradición sociológica, ha tenido un enorme desarrollo teórico en la década del '50, pero con el que se pretendía implicar un fenómeno específico de "subcultura". Se habló de subculturas delictivas y pandillas juveniles, generalmente aunque no siempre, vinculadas a la comisión de acciones delictivas o cuanto menos transgresoras. Claro que las explicaciones demostraron ser insuficientes cuando actos vandálicos fueron cometidos ya no por los jóvenes, feos, sucios y malos de siempre, sino por los jóvenes ricos y, muchas veces, aunque no siempre, poderosos. Ya empezó a costar hablar 
de acciones delictivas, de vandalismo, de alevosía, de violencia desmesurada, y empezaron a ensayarse otras explicaciones más afines a los determinantes estructurales que promueven una cultura adolescente, entre cuyos valores devaluados por el contexto general hay espacio para acciones desreguladas de violencia individual que podrían estar denotando un malestar en la cultura, producto de los cambios vertiginosos en el mercado y sus formas privilegiadas de anclaje y construcción de soportes identitarios, pero nunca un tema de agenda para la política criminal. Cuando el vandalismo es cometido por los niños ricos con tristeza, se apela a la ausencia de políticas de juventud y políticas sociales que tengan al segmento joven como destinatario; cuando los mismos actos vandálicos son cometidos por los chicos pobres con hambre, se habla de inseguridad, de pánico social y de la necesidad de endurecer el sistema penal y bajar la edad de imputabilidad penal, y habilitar medidas más duras para quienes pasan al acto.

Justamente allí, en la reducción de la complejidad de los fenómenos, aparecen los cazadores de brujas que, muñidos de su red de pesca gigante (S. Cohen, 1989), hacen redadas capturando a aquellos perdedores sociales, indivualistas negativos por defecto y no elección, para los cuales no hay diferencia en el trato, así sean víctimas o victimarios.

Mientras tanto, como dice De Giorgi, "el problema resta intacto, los caracteres estructurales permanecen inobservables: los proyectos sirven para legitimar la demanda de nuevos proyectos en virtud de que las patologías siguen subsistiendo" (De Giorgi, 1997: 87). Los fantasmas del miedo y la injusticia se fortalecen ante la impunidad y el descrédito de las instituciones. El malestar sobrante redunda; la violencia, agradecida. 
Ni bandas ni pandillas: la miopía de las teorías de las subculturas para explicar la violencia juvenil - S. Guemureman

\section{Bibliografía consultada}

Bleichmar, S. (2005). "Tiempos difíciles. La identificación en la adolescencia", en La subjetividad en riesgo, Colección Psicoanálisis, sociedad y cultura, Editorial Topía, buenos Aires.

Castel, Robert (1995). Las metamorfosis de la cuestión social. Una crónica del salariado, Editorial Paidós, Argentina.

Cloward, R.- Ohlin, L (1960). Delinquency and opportunity. A theory of delinquent gangs, The Free press of Glencoe, Illinois.

Cohen, A. (1955). Delinquent boys: the culture of the gang, Chicago, Free Press.

David, P. (1974). Sociología Criminal juvenil, Buenos Aires, Desalma.

De Giorgi, Raffaele (1997). "Riesgo, malestar y desviación: reflexión sobre la violencia y los menores", en Revista Delito y Sociedad, Revista de Ciencias Sociales, No 9-10, Buenos Aires.

Diarios Clarín y La Nación. Revisión de noticias vinculadas con los casos desde el 19/01/2006 hasta el 30/04/2006.

Duchasky, S.; Corea, C. (2002). Chicos en banda. Los caminos de la subjetividad en el camino de las instituciones, Editorial Paidós, Buenos Aires.

Entrevista a Marcelo Urresti, en Diario Página 12, 23 de abril del 2006.

Matza, D. (1961). "Juvenile delinquency and subterranean values", en American Sociologycal Review, vol. 26.

Madrenas i Boadas, C. (1990). “Una visión de la teoría de las subculturas criminales: Albert. K. Cohen y Richard A. Cloward y Lloyd E. Ohlin", en Revista Doctrina Penal, Buenos Aires.

Melossi, D. (1997). "La radicación cultural del control social (o de la imposibilidad de la traducción): reflexiones a partir de la culturas italiana y norteamericana con respecto al control social" en Revista Delito y Sociedad, Revista de Ciencias Sociales, No 9-10, Buenos Aires.

Mires, Fernando (1998). El malestar en la barbarie. Erotismo y cultura en la formación de la sociedad política, Editorial Nueva Sociedad, Venezuela.

Pavarini, M. (2004). "El «Nuevo mundo» del control social", en El control social en el fin de siglo, Secretaría de Postgrado de la Facultad de Ciencias Sociales, Oficina de Publicaciones del Ciclo básico Común, Universidad de Buenos Aires.

Senett, R. (2000). La corrosión del carácter. Las consecuencias personales del trabajo en el nuevo capitalismo, Editorial Anagrama, Barcelona. 
Spergel. Irving A. (2002). "Pandillas juveniles: una crítica de estudios recientes", en Revista Delito y Sociedad, Revista de Ciencias Sociales, No 17, Buenos Aires.

Sykes, G.-Matza, D. (2004). “Técnicas de neutralización: una teoría de la delincuencia", en Revista Delito y Sociedad, Revista de Ciencias Sociales $\mathrm{N}^{\circ} 20$ (artículo original, publicado en American Sociologycal Review Vol. 22 Agosto de 1975). 